\title{
Tracheoesophageal fistula due to migration of a self-expanding esophageal stent successfully treated with a silicone "Y" tracheobronchial stent
}

\author{
Jose Melendez, MD, ${ }^{\mathrm{a}}$ Danny Chu, MD, ${ }^{\mathrm{b}}$ Faisal G. Bakaeen, MD, ${ }^{\mathrm{b}}$ and Roberto F. Casal, MD, ${ }^{\mathrm{a}}$ Houston, Tex
}

Tracheoesophageal fistula (TEF) due to erosion of esophageal stents into the trachea has been reported. ${ }^{1-5}$ However, the reported management strategies involve surgical stent removal and TEF repair or endoscopic removal of the esophageal stent followed by re-stenting of the esophagus. We report our successful management of this complication with a silicone $\mathrm{Y}$ tracheobronchial stent and without removal of the esophageal stent.

\section{CLINICAL SUMMARY}

An esophageal stricture secondary to a poorly differentiated squamous cell carcinoma of the mid-esophagus was diagnosed in a 56-year-old man, for which he underwent balloon dilation. This procedure resulted in esophageal perforation requiring primary surgical repair with intercostal muscle pedicle buttressing. One month after surgery, to palliate the patient's dysphagia, a "covered" 10-cm-long selfexpanding esophageal stent (Ultraflex; Boston Scientific Corp, Natick, Mass) was placed with its proximal end approximately $2 \mathrm{~cm}$ below the upper esophageal sphincter. The esophageal carcinoma was surgically and radiographically staged as T4 N0 M0, and the patient received definitive chemoradiation. Approximately 2 months after esophageal stent placement, a persistent cough developed in the patient, particularly when eating. Computed tomography of the chest (Figure 1, A) showed a possible defect on the posterior tracheal wall overlying the proximal end of the esophageal stent. A barium swallow confirmed the presence of a TEF, with contrast in the mid-lower trachea and left main stem bronchus (Figure 1,B). Flexible bronchoscopy showed the anterior aspect of the proximal end of the esophageal stent eroding through the posterior tracheal wall and protruding into the tracheal lumen approximately

\footnotetext{
From the Departments of Pulmonary and Critical Care Medicine ${ }^{\mathrm{a}}$ and Cardiothoracic Surgery, ${ }^{\mathrm{b}}$ Baylor College of Medicine, Houston, Tex.

Disclosures: Authors have nothing to disclose with regard to commercial support.

Received for publication Dec 24, 2010; accepted for publication Feb 9, 2011; available ahead of print Mach 23, 2011.

Address for reprints: Roberto F. Casal, MD, Department of Pulmonary and Critical Care Medicine, Baylor College of Medicine, Michael E. DeBakey VA Medical

Center, 2002 Holcombe Blvd, Pulmonary Section 111i, Houston, TX 77030 (E-mail: casal@bcm.edu)

J Thorac Cardiovasc Surg 2011;141:e43-4 0022-5223/\$0.00

Published by Elsevier Inc. on behalf of The American Association for Thoracic Surgery

doi:10.1016/j.jtcvs.2011.02.002
}

$5.5 \mathrm{~cm}$ from the carina (Figure 1,C). In addition, a $60 \%$ obstruction of the left main stem bronchus due to extrinsic compression by the esophageal stent was also observed. A multidisciplinary team formed by thoracic surgeons, interventional pulmonologists, and gastroenterologists evaluated the patient. The patient was not considered to be a surgical candidate because of comorbid conditions and a locally advanced esophageal tumor in proximity of the TEF. A rigid bronchoscopy was performed, and an $18 \times 14 \times 14$ Dumon Y-stent (Novatech, La Ciotat, France) was placed. The proximal end of the Y-stent was approximately $2.5 \mathrm{~cm}$ proximal to the TEF. After deployment of the Y-stent, the esophageal stent was still protruding into the trachea, creating a "fold" on the posterior aspect of the Y-stent. We briefly inflated a balloon dilator (up to $18 \mathrm{~mm}$ ) within the Y-stent, displacing the esophageal stent posteriorly and sealing the TEF (Figure 1, D). The esophageal stent was never removed. The patient tolerated the procedure well, and the repeat barium swallow was normal. Six months after the tracheal stent placement and 11 months after his initial diagnosis, the patient is asymptomatic, eating orally, and gaining weight.

\section{DISCUSSION}

Esophageal stents are commonly used to palliate malignant strictures, and stent-related complications, such as lung aspiration, hemorrhage, and esophageal perforation, occur in $10 \%$ to $20 \%$ of cases. ${ }^{3}$ Stent migration into the trachea is rare but potentially life-threatening. Several surgical interventions have been reported for the management of self-expanding esophageal stents causing TEF. ${ }^{1,4,5}$ The reported endoscopic strategies involve bronchoscopic removal of the esophageal stent through the tracheal tear followed by re-stenting of the esophagus, telescoping of a second esophageal stent to realign the one that migrated, and deployment of a metallic self-expanding tracheal stent. $^{3}$

Although the use of silicone Y-stents for the management of malignant TEF has been extensively described, to the best of our knowledge, its use for TEF caused by a selfexpanding esophageal stent has not been reported. We chose not to place a self-expanding metal stent in the trachea overlying the esophageal stent with the concern of potential necrosis of the tracheal wall in between these 2 stents. We did suspect before the procedure that the 


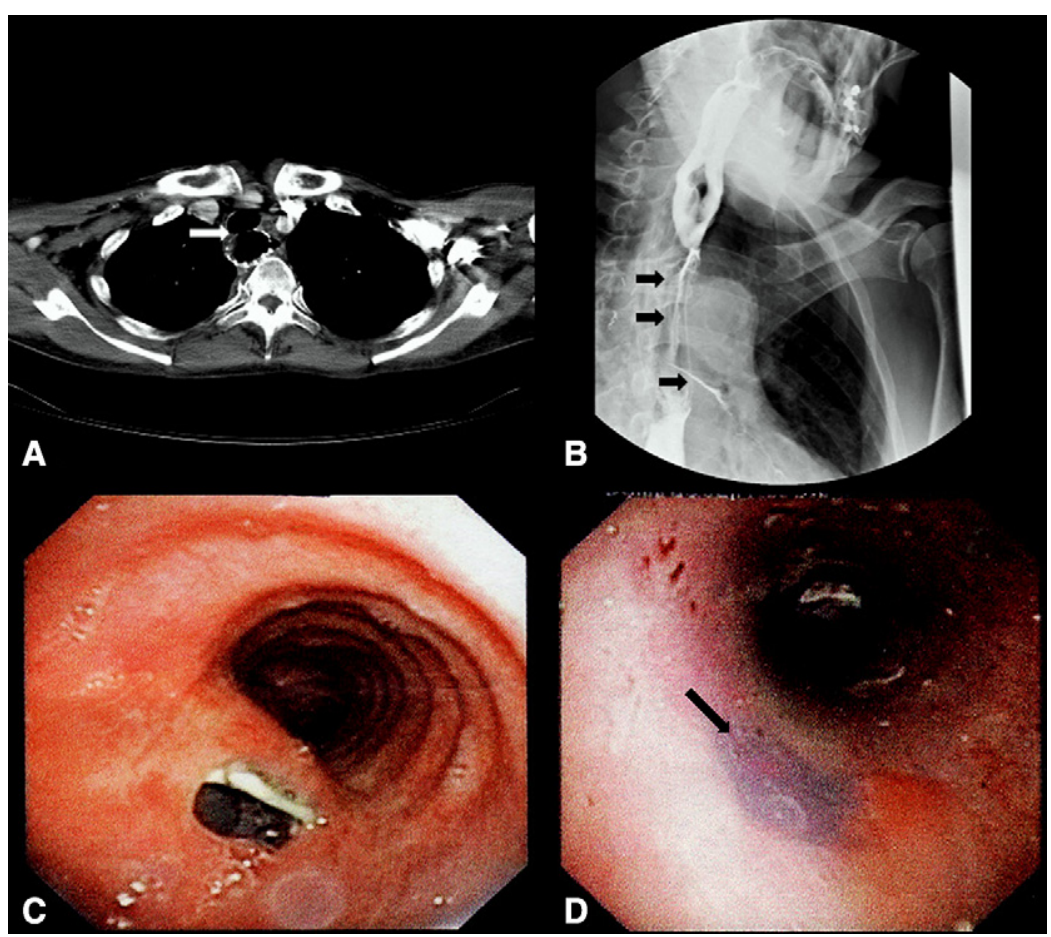

FIGURE 1. A, Computed tomography of the chest showing a possible defect on the posterior tracheal wall overlying the proximal end of the esophageal stent. B, Barium swallow study demonstrating contrast in the distal half of the trachea and the left main stem bronchus. C, Bronchoscopic view of the proximal end of the esophageal stent eroding through the posterior wall of the trachea creating a fistula. $\mathrm{D}$, Inner view of the proximal portion of the silicone Y-stent tightly sealing the tracheal defect.

protrusion of the metallic esophageal stent would not allow our silicone stent to seal the defect properly. As mentioned above, we solved this problem by inflating a balloon dilator within the Y-stent and slightly displacing the esophageal stent posteriorly. Unlike most cases in the literature, the TEF was completely sealed without removing the esophageal stent, which allowed the patient to continue oral alimentation.

\section{CONCLUSIONS}

Given the relatively high morbidity and mortality associated with surgical repair of TEF, we cautiously propose our multidisciplinary approach and minimally invasive strategy to manage patients with relatively small TEF caused by esophageal stent migration. Although our procedure was uneventful and our patient had an excellent clinical course, further studies are needed to corroborate the efficacy and safety of this approach.

\section{References}

1. Conti M, Ferraro P, Martin J, Duranceau A. Esophageal stent migration into the trachea. J Thorac Cardiovasc Surg. 2007;134:1084-5.

2. Hendra KP, Saukkonen JJ. Erosion of the right mainstem bronchus by an esophageal stent. Chest. 1996;110:857-8.

3. Katsanos K, Sabharwal T, Koletsis E, Fotiadis N, Roy-Choudhury S, Dougenis D, et al. Direct erosion and prolapse of esophageal stents into the tracheobronchial tree leading to life-threatening airway compromise. J Vasc Interv Radiol. 2009; 20:1491-5

4. Han Y, Liu K, Li X, Wang X, Zhou Y, Gu Z, et al. Repair of massive stent-induced tracheoesophageal fistula. J Thorac Cardiovasc Surg. 2009;137:813-7.

5. Shichinohe T, Okushiba S, Morikawa T, Kitashiro S, Manase H, Kawarada Y, et al. Salvage of a massive esophago-tracheal fistula resulting from a stenting treatment. Dis Esophagus. 2006;19:299-304. 